\title{
Preliminary study of the chemical composition of rice milling fractions stabilized by microwave heating
}

\begin{abstract}
The present paper presents a preliminary study of the chemical composition of local stabilized rice bran. The four rice-bran milling fractions, after stabilization by microwave heating on site at the rice mill, were analyzed for their chemical composition. The content of all fractions tested (in $\mathrm{g} / 100 \mathrm{~g}$ ) consisted of 8.7-18.9 fat, 8.8-15.2 protein, 8.5-12.6 moisture, 4.2-7.7 ash, 22.2-44.8 total carbohydrates (by difference) and 18.3-30.5 total dietary fibre. It is encouraging to note that total phenolic compounds of all fractions were detected at 257$488 \mathrm{mg}$ ferulic acid equivalent per $100 \mathrm{~kg}$, while carotenoid contents were found to be in the range of 58.7-216 $\mu \mathrm{g} / 100 \mathrm{~g}$. The amino acid composition varied within wide limits with proline, histidine and threonine as the amino acids. Higher concentrations of amino acids found (in decreasing order) were arginine, glutamic acid, aspartic acid and serine. Phosphorus and potassium were among the major mineral constituents of rice bran, with values up to $1633 \mathrm{mg} / 100 \mathrm{~g}$. The first rice bran fraction was found to be highest in energy, fat and minerals and could be a very good source of dietary fiber and other nutrients.
\end{abstract}

Keyword: rice bran, stabilization at mill, chemical composition, minerals, amino acids, carotenoids, total phenolic compounds 